\title{
Preparation of large size ZTA ceramics with eccentric circle shape by microwave sintering
}

\author{
Yongqiang $\mathrm{CHEN}^{a, b}$, Bingbing $\mathrm{FAN}^{b, c, *}$, Gang $\mathrm{SHAO}^{b}$, Rui ZHANG ${ }^{a, b,{ }^{*}}$ \\ ${ }^{a}$ Zhengzhou University of Aeronautics, Henan 450015, China \\ ${ }^{b}$ School of Materials Science and Engineering, Zhengzhou University, Henan 450001, China \\ ${ }^{c}$ Sinosteel Luoyang Institute of Refractories Research Co., Ltd., Henan 471039, China
}

Received: April 22, 2016; Revised: August 01, 2016; Accepted: August 08, 2016

(C) The Author(s) 2016. This article is published with open access at Springerlink.com

\begin{abstract}
Ultra-large zirconia toughened alumina (ZTA, mass ratio of $\mathrm{Al}_{2} \mathrm{O}_{3}$ and $\mathrm{ZrO}_{2}$ is 78:22) ceramics with eccentric circle shape were successfully sintered by microwave sintering with a multi-mode cavity at $2.45 \mathrm{GHz}$. The dimension of ZTA ceramics (green body) is $165 \mathrm{~mm}$ (outer diameter) $\times 25 \mathrm{~mm}$ (thickness). The optimized sintering temperature of microwave sintering is about $1500{ }^{\circ} \mathrm{C}$ for $30 \mathrm{~min}$, and the total sintering time is about $4 \mathrm{~h}$ which is much shorter than that of conventional sintering. An auxiliary-heating insulation device was designed based on the principle of local caloric compensation to guarantee the intact sintered samples. With the increasing of sintering temperature, more and more microwave energy is absorbed within the entire sample, volumetric densification performs, and phases shift from $\mathrm{m}-\mathrm{ZrO}_{2}$ phase to $\mathrm{t}-\mathrm{ZrO}_{2}$ phase and cause $\mathrm{Al}_{2} \mathrm{O}_{3}$ grain growth.
\end{abstract}

Keywords: large size ZTA ceramics; eccentric circle shape; microwave sintering; local caloric compensation

\section{Introduction}

Zirconia toughened alumina (ZTA) ceramics are considered as promising structural materials for their high toughness, hardness, wear resistance, high temperature anticorrosion, and chemical stability [1]. These unique properties of ZTA ceramics lead to many industrial applications including cutting tools, wear parts [2], and seal valves. Figure 1 shows the industrial application of ZTA ceramics as seal valves. As one kind of sealing part, commercially available large size ZTA ceramics with eccentric circle shape are prepared

* Corresponding authors.

E-mail: B. Fan, fanbingbing@zzu.edu.cn;

R. Zhang, zhangray@zzu.edu.cn by conventional sintering techniques, which show many disadvantages of long dwell time, high energy consumption, serious pollution, and high cost $[3,4]$. Microwave sintering as a new heating method is receiving more and more attention in the field of fabricating high-temperature materials [3,5-9]. Some of the most significant advantages of microwave sintering are volumetric energy absorption with high heating rate, short duration, and less power consumption, which overcome the disadvantages of conventional sintering mentioned above. Many researchers have reported microwave sintering of ZTA ceramics and relevant microwave sintering mechanism [4]. Nevertheless, samples sintered in these works present small dimensions and simple shapes which limit this sintering technique to laboratory application 


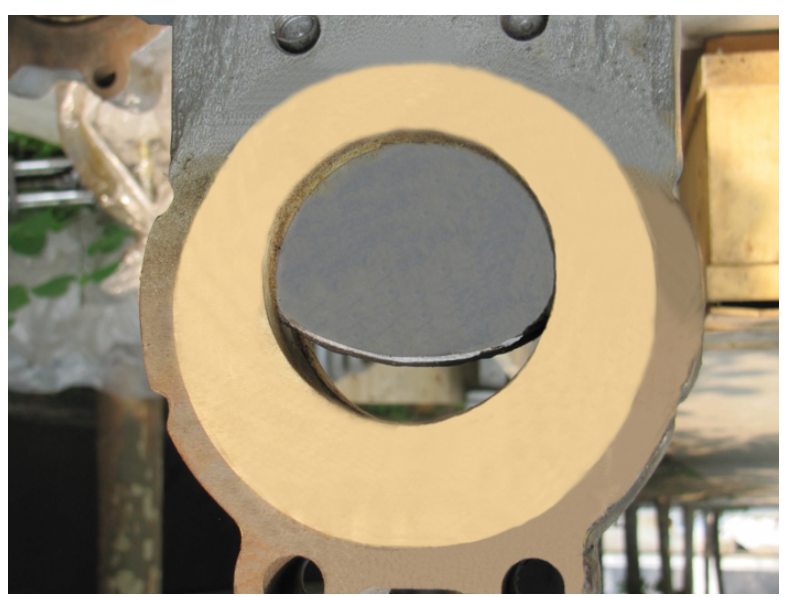

Fig. 1 Industrial application of ZTA ceramics as seal valves.

[10]. Moreover, due to the volumetric heating characteristic of microwave sintering, the uneven distribution of quality generates uneven distribution of heat. The different sintering temperature at related areas causes uneven shrinkage leading to cracking. The thermal stress produced in the process of heat conduction could cause cracking of samples. In the latest study, only one large size sheet of kaolin with complex shape was successfully sintered in a microwave multi-mode cavity [10]. The explorations of microwave sintering process on special-shaped and large size ZTA ceramics are still nonexistent.

In the present work, ultra-large industrial ZTA ceramics with eccentric circle shape are sintered successfully by microwave sintering method and the relevant properties of samples are discussed. A reasonable auxiliary-heating insulation device is also designed to ensure the samples' quality.

\section{Experimental procedures}

\section{1 Raw materials and modeling}

Alumina $\left(\mathrm{Al}_{2} \mathrm{O}_{3}\right.$, Zhengzhou Tianma, $\left.99 \%, d_{50}=40 \mu \mathrm{m}\right)$ and $3 \mathrm{~mol} \%$ yttria partially stabilized zirconia $\left(\mathrm{ZrO}_{2}\right.$, Shandong Guangtong, $99 \%, d_{50}=40 \mu \mathrm{m}$ ) were used as starting materials in this study. $78 \mathrm{wt} \% \mathrm{Al}_{2} \mathrm{O}_{3}$ and $22 \mathrm{wt} \% \mathrm{ZrO}_{2}$ powders were mechanically mixed for $2 \mathrm{~h}$ using ball milling method with $5 \mathrm{~mm}$ zirconia balls as grinding media in a polypropylene container at constant speed of $300 \mathrm{rpm}$. Forming of the initial ZTA green body samples was carried out at Zhengzhou Dingsheng Engineering Technology Company by slip casting method, and the initial density is $2.54 \mathrm{~kg} / \mathrm{m}^{3}$.

\section{2 Microwave sintering process of ZTA ceramics}

The green ZTA ceramics, with the dimension of $165 \mathrm{~mm}$ (outer diameter) $\times 25 \mathrm{~mm}$ (thickness) as shown in Fig. 2(a), were sintered in a microwave chamber with the resonant mode of TE666 (WXD20S-07, China Nanjing San Le Microwave Equipment). The microwave frequency was $2.45 \mathrm{GHz}$ with maximum input power of $10 \mathrm{~kW}$. The selected

(a) Green body

(b) Sintered sample

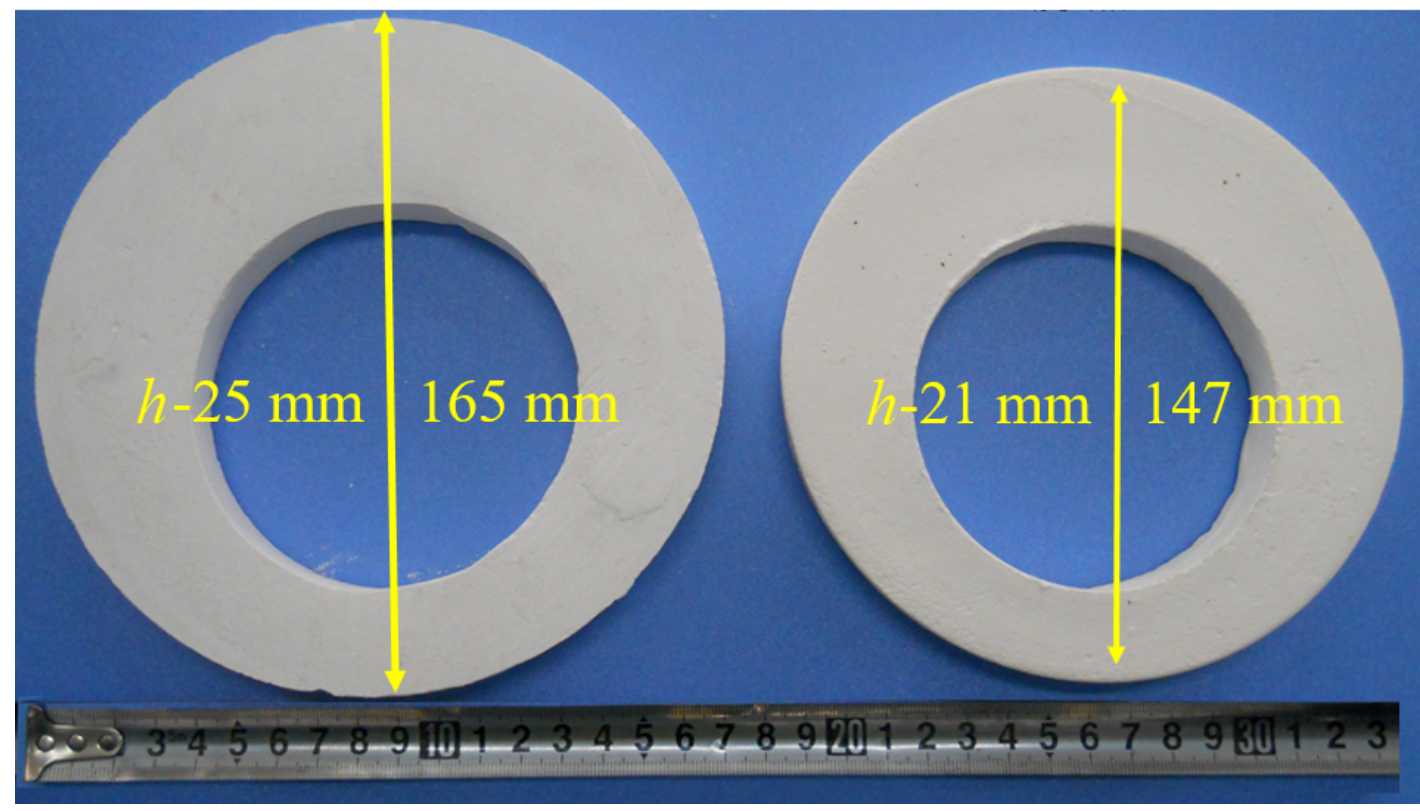

Fig. 2 Dimensions of ZTA ceramics: (a) green body, (b) sintered sample. 
sintering temperature was $1350{ }^{\circ} \mathrm{C}, 1400{ }^{\circ} \mathrm{C}, 1450{ }^{\circ} \mathrm{C}$, $1500{ }^{\circ} \mathrm{C}$, and $1550{ }^{\circ} \mathrm{C}$ for $30 \mathrm{~min}$ with a self-made auxiliary-heating insulation device, while the volumetric heating was only in the case of the direct microwave sintering. Microwave heating rate was controlled by adjusting the input power; the temperature was monitored by using a monochromatic optical fiber infrared thermometer (OI-T6I2-B-1-type, GOIDSUN, USA) with initial display temperature of $600{ }^{\circ} \mathrm{C}$. The temperature was calibrated by Ferro process temperature control rings (PTCR). So the input power was adjusted at $50 \mathrm{~W} / \mathrm{min}$ before $600{ }^{\circ} \mathrm{C}$. Then, with thermo detector displaying the values, the input power was adjusted to increase about $500 \mathrm{~W}$ when the heating rate was under $7{ }^{\circ} \mathrm{C} / \mathrm{min}$. The basic framework of the device was a square box composed of two layers of mullite light bricks, and four silicon carbide rods which were packed by mullite insulation cotton and uniformly distributed in interlayer of each side. Figures 3(a) and 3(b) show the sketch of the original and optimized auxiliary-heating insulation device, respectively. The numbers of 1,2 , and 3 in these figures indicate mullite light bricks, silicon carbide rods, and samples, respectively. The samples were covered by mullite insulation cotton with a thermometer hole.

\section{3 Characterization}

The morphological features of the fracture surface of ZTA ceramics were examined by scanning electron microscopy (SEM, JEOL, JSM-7001F). The strength of ZTA ceramics was measured by the three-point bending method using an electronic universal testing

machine (WD-P4504). The Vickers hardness $\left(H_{\mathrm{V}}\right)$ was carried out using a diamond indenter (TH-700) at a load of $20 \mathrm{kgf}$ with an indentation period of $20 \mathrm{~s}$. Ten $H_{\mathrm{V}}$ measurements were used to obtain an average value. The phase compositions of sintered samples were measured by X-ray diffraction (XRD, XD-30). The density of the green compacts was determined by Archimedes method using mercury displacement. The bulk density of sintered samples was determined by water immersion (Standard Method ASTM C20).

\section{Results and discussion}

\section{1 Microwave sintering process of ZTA ceramics}

Figure 4(a) shows input power, reflected power, and sintering temperature versus sintering time for cracked sample. Figure 4(b) is the photograph of cracked irregular ZTA ceramics, which was sintered using original auxiliary-heating insulation device as shown in Fig. 3(a). The total sintering time of ZTA ceramics was $250 \mathrm{~min}$ including dwell time of $30 \mathrm{~min}$, whereas it cost about $170 \mathrm{~h}$ to prepare such ZTA products by traditional sintering (based on practical data from industrial processing at Zhengzhou Dingsheng Engineering Technology Company). It also can be found that the reflected power increases with increasing of input power before $100 \mathrm{~min}$. In the next $50 \mathrm{~min}$, sintering temperature continuously rises, while the reflected power is declined slightly; then, the input power and reflected power tend to be stable, which indicates the microwave coupling ability of the sample become stronger and stronger with the increasing of heating temperature [11-13]. However, the heating rate
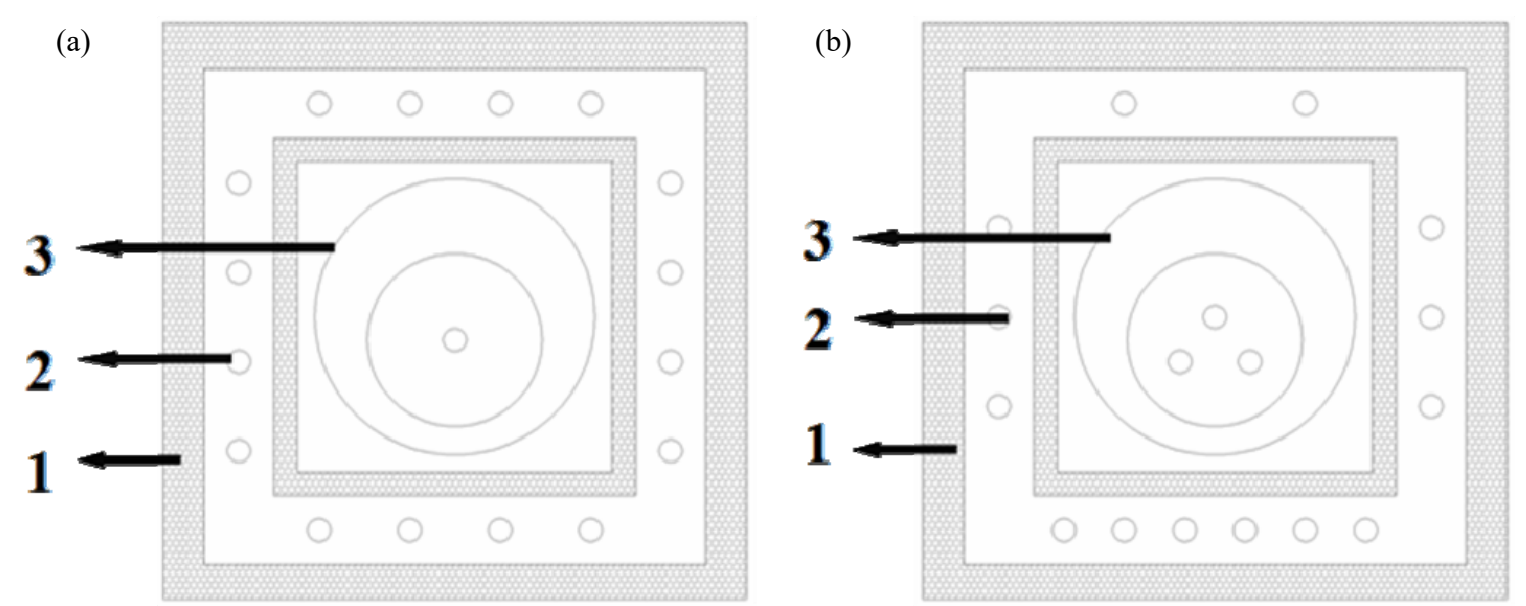

Fig. 3 Sketch of auxiliary-heating insulation device: (a) original structure, (b) optimized structure. 1-mullite light brick, 2-silicon carbide rod, 3-sample. 

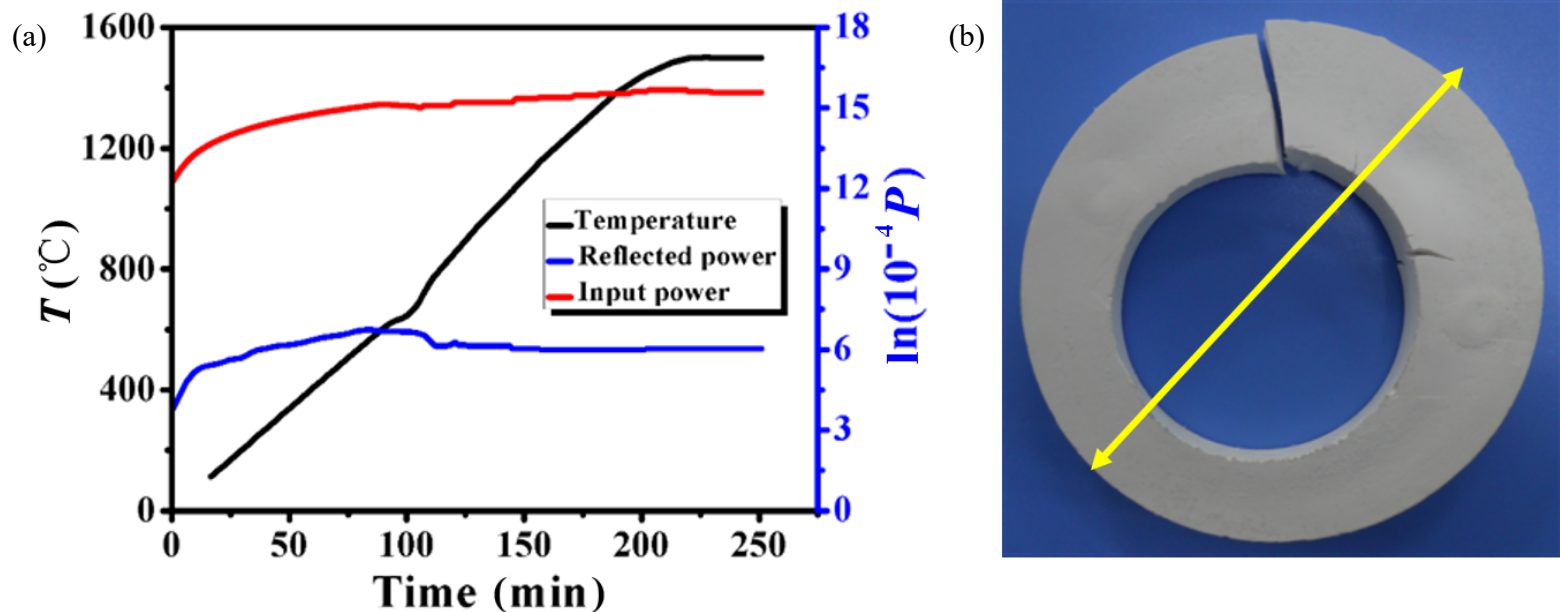

Fig. 4 (a) Input power, reflected power, and sintering temperature vs. sintering time for cracked sample; (b) cracked ZTA ceramics.

slows down gradually because the sample radiates more heat at high temperature. Meanwhile, at high temperature the $\mathrm{SiC}$ susceptor tends to screen the electric field leading to surface heating mechanism [14]. The mass distribution of ZTA ceramics is asymmetrical for its eccentric ring structure; in the case of uniform distribution of silicon carbide rods, the large mass part absorbed microwave intensely causing local heat gather, which may produce great thermal stress in the process of heat conduction, then cause structure crack of ZTA ceramics. The fracture occurs at the junction between large mass area and small mass area due to its drastic heat conduction, as shown in Fig. 4(b). It also can be seen that this sample has only one completely cracked part. It may be explained as that, when the sample completely cracks, two new surfaces are produced, the trapping heat transfers to the new surfaces which reduces the heat conduction from the large mass part to the small mass part.
Figure 5(a) gives the input power, reflected power, and sintering temperature versus sintering time for irregular ZTA ceramics. The photograph of intact sample sintered by optimized auxiliary-heating insulation device (Fig. 3(b)) is shown in Fig. 5(b). It can be seen that the sintered ZTA ceramics is intact, and the total sintering time is $250 \mathrm{~min}$ the same as which shows in Fig. 4(a). But in Fig. 5(a), the heating temperature is already $700{ }^{\circ} \mathrm{C}$ when the sintering time is $80 \mathrm{~min}$, which indicates that the heating rate of ZTA ceramics with optimized auxiliary-heating insulation device is faster than the original device at this prior period. Due to the special distribution of auxiliary heating rods, the sample has a fast heating rate before $700{ }^{\circ} \mathrm{C}$. Compared with Fig. 4(a), we can see that the reflected power and input power values are similar after stabilization. However, the heating rate of the sample is slower than the cracked sample in the last (a)

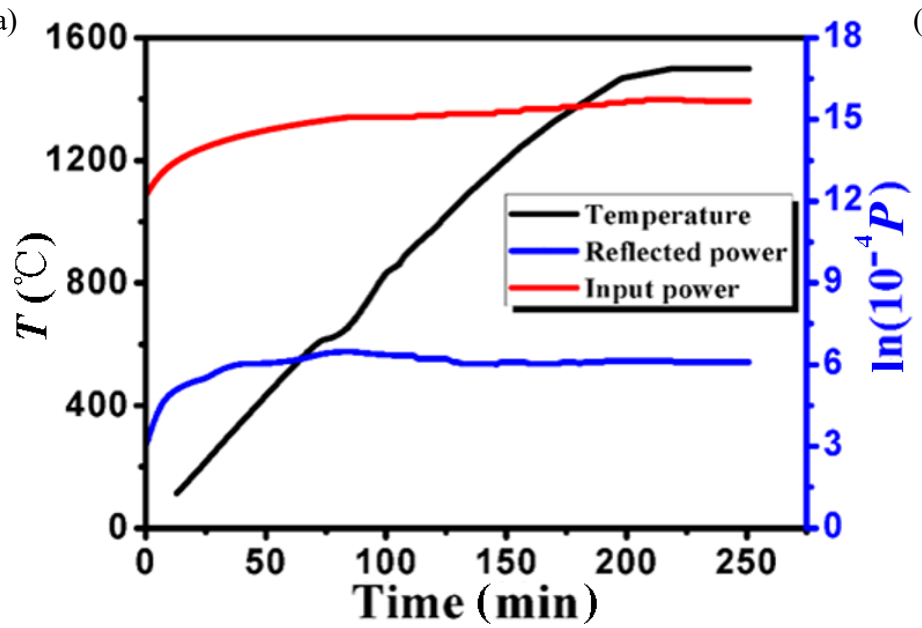

(b)

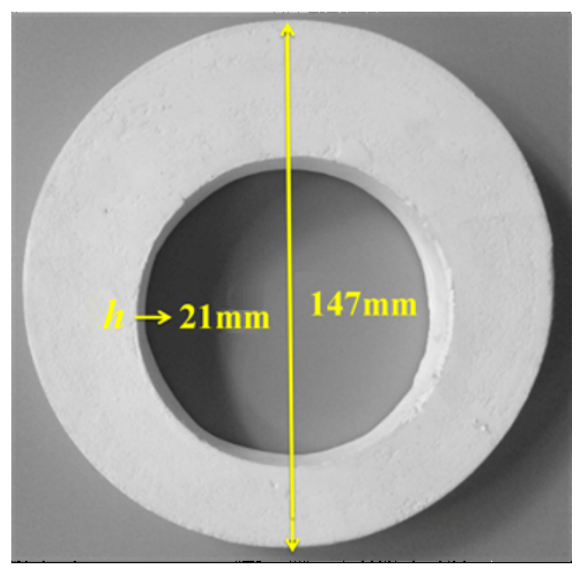

Fig. 5 (a) Input power, reflected power, and sintering temperature vs. sintering time for intact sample; (b) intact ZTA ceramics. 
period; the uneven distribution of silicon carbide rods has affected the heating rate under the same electromagnetic field [14].

\section{2 Characteristic of ZTA ceramics fabricated by microwave sintering}

Figure 6 shows the bending strength and porosity of ZTA ceramics at different sintering temperatures. The bending strength of ZTA ceramics increases as the sintering temperature increases. The maximum value is $435 \mathrm{MPa}$ at $1500{ }^{\circ} \mathrm{C}$. The porosity decreases rapidly from 1400 to $1450{ }^{\circ} \mathrm{C}$. The lowest porosity is about $0.1 \%$ at $1500{ }^{\circ} \mathrm{C}$.

Figure 7 shows the Vickers hardness and bulk density versus sintering temperature of ZTA ceramics. Green ware bulk density of ZTA ceramics is $2.54 \mathrm{~kg} / \mathrm{m}^{3}$. It can be seen that the bulk density increases uniformly with the increase of sintering temperature from 1350 to $1500{ }^{\circ} \mathrm{C}$; the maximum density is $4.01 \mathrm{~kg} / \mathrm{m}^{3}$ at $1500{ }^{\circ} \mathrm{C}$. However, the highest hardness value of ZTA sample sintered at $1450{ }^{\circ} \mathrm{C}$ is 14.2 GPa.

According to industrial application standard, as a

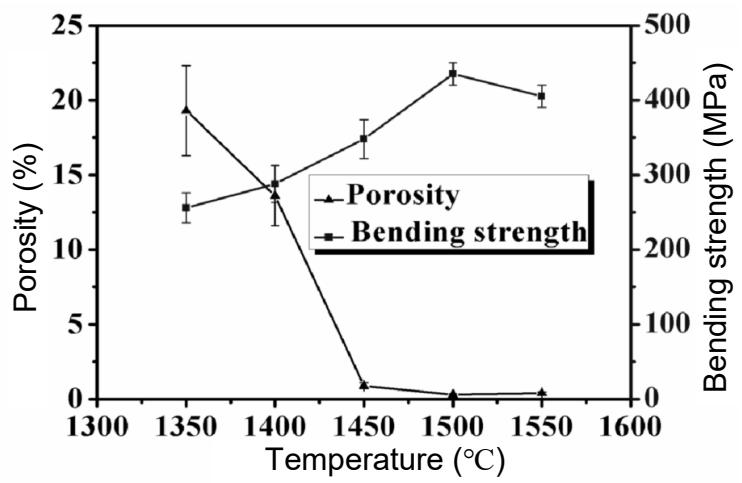

Fig. 6 Bending strength and porosity of ZTA ceramics.

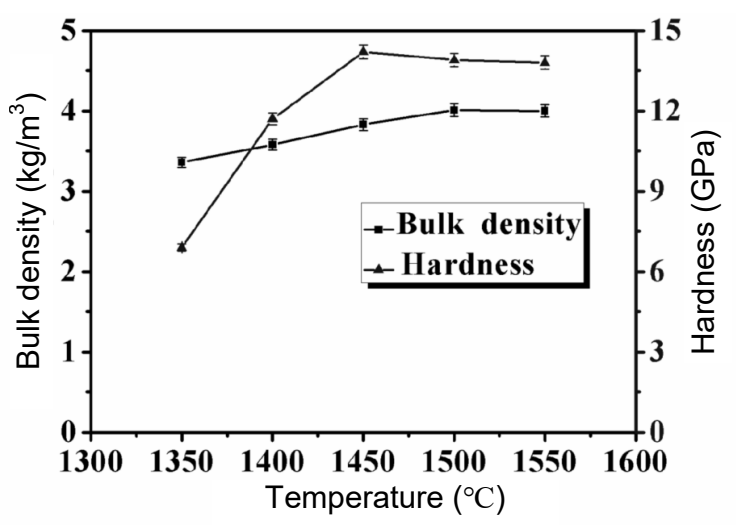

Fig. 7 Vickers hardness and bulk density of ZTA ceramics. valve sealing part, the bending strength of the ZTA ceramics is $426 \mathrm{MPa}$. The bulk density and micro-hardness are $4.03 \mathrm{~kg} / \mathrm{m}^{3}$ and $13.8 \mathrm{GPa}$, respectively. The ZTA ceramics sintered by microwave in this work can satisfy the above requirement (based on practical data from industrial processing at Zhengzhou Dingsheng Engineering Technology Company).

Figure 8 shows the microstructure of ZTA ceramics prepared by microwave sintering at different temperatures. It can be seen that sample sintered at $1350{ }^{\circ} \mathrm{C}$ shows a less dense microstructure with loose particles, as shown in Fig. 8(a). A dense and homogeneous microstructure is observed for samples sintered at temperatures higher than $1400{ }^{\circ} \mathrm{C}$, as shown in Figs. 8(b)-8(e). The grains have been bonded together obviously, as the arrow shown in Fig. 8(b); the areas are dense especially near the $\mathrm{Al}_{2} \mathrm{O}_{3}$ grains (Fig. 8(f)) [15]. $\mathrm{Al}_{2} \mathrm{O}_{3}$ grains constantly couple with microwave forming heating sources leading to local high temperature, which promotes the grain growth of $\mathrm{Al}_{2} \mathrm{O}_{3}$. With continually increasing sintering temperature, more and more microwave energy is absorbed within the entire sample and volumetric
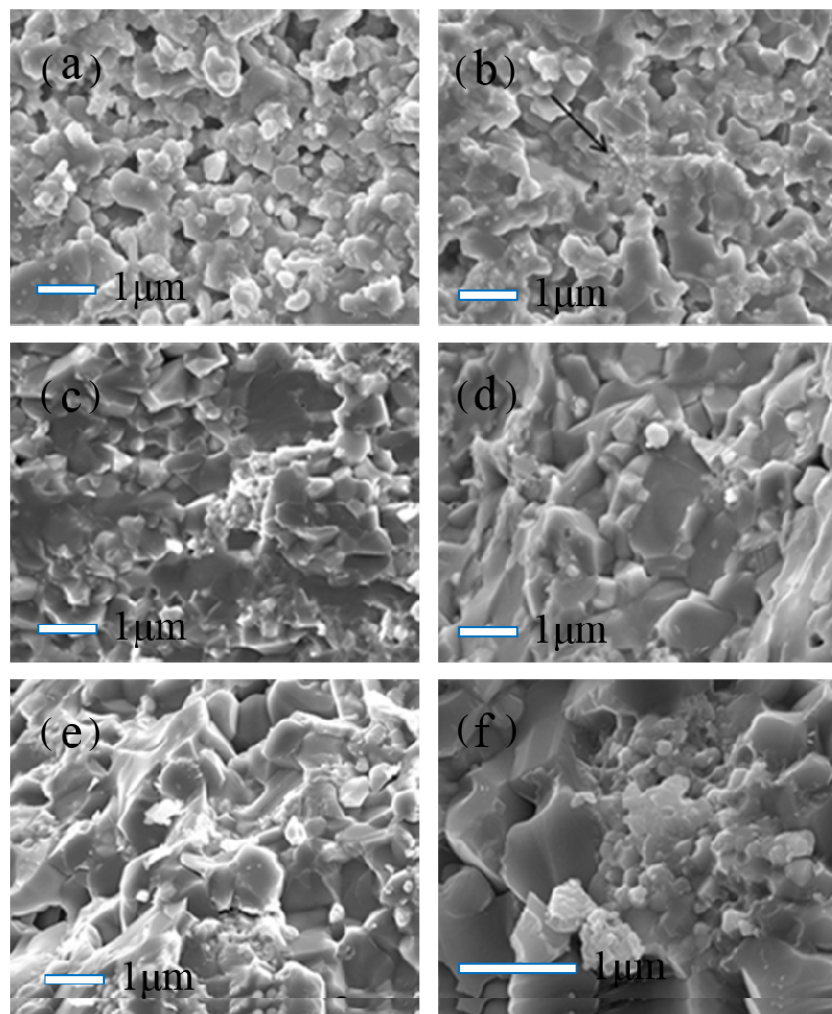

Fig. 8 Microstructure of ZTA ceramics at different sintering temperatures: (a) $1350{ }^{\circ} \mathrm{C}$, (b) $1400{ }^{\circ} \mathrm{C}$, (c) $1450{ }^{\circ} \mathrm{C}$, (d) $1500{ }^{\circ} \mathrm{C}$, (e) $1550{ }^{\circ} \mathrm{C}$, (f) $1450{ }^{\circ} \mathrm{C}$. 
densification performs, creating the dense structure at $1500{ }^{\circ} \mathrm{C}$ as illustrated in Fig. 8(d). Due to the growth temperature of $\mathrm{Al}_{2} \mathrm{O}_{3}$ grains is lower than that of $\mathrm{ZrO}_{2}$ grains, normally $\mathrm{Al}_{2} \mathrm{O}_{3}$ matrix shows relatively large grains compared to $\mathrm{ZrO}_{2}$ grains, and $\mathrm{ZrO}_{2}$ grains are formed at the interphase of $\mathrm{Al}_{2} \mathrm{O}_{3}$ large particles, as shown in Fig. 8(e). All mechanical performances are no better and even worse up to $1550{ }^{\circ} \mathrm{C}$. This behavior may be related to over-sintering occurring with much more larger $\mathrm{Al}_{2} \mathrm{O}_{3}$ grains.

Figure 9 is the XRD patterns of green body and ZTA ceramics at different microwave sintering temperatures. The pattern of green body shows that the original ZTA ceramics contain monoclinic zirconia $\left(\mathrm{m}-\mathrm{ZrO}_{2}\right)$ and alumina $\left(\mathrm{Al}_{2} \mathrm{O}_{3}\right)$. The peak of $\mathrm{m}-\mathrm{ZrO}_{2}$ is disappeared and the obvious peak of tetragonal zirconia $\left(\mathrm{t}-\mathrm{ZrO}_{2}\right)$ could be observed at $1350{ }^{\circ} \mathrm{C}$. With the increasing of sintering temperature, due to the microwave energy, phases shift from $\mathrm{m}-\mathrm{ZrO}_{2}$ phase to $\mathrm{t}-\mathrm{ZrO}_{2}$ phase, and the peak intensity of $\mathrm{t}-\mathrm{ZrO}_{2}$ constantly intensifies up to $1550{ }^{\circ} \mathrm{C}$, which is opposite to Ref. [16]. This phase transformation has great influence on the bending strength. It also can be seen that the peaks of alumina also constantly are enhanced with the increasing of sintering temperature, which indicates the crystallinity of ZTA ceramics increases gradually, consistent with the SEM results from Fig. 8, and also proves that microwave sintering can promote the grain growth of alumina.

\section{Conclusions}

In this paper, the microwave sintering process of large size ZTA ceramics with eccentric circle shape was

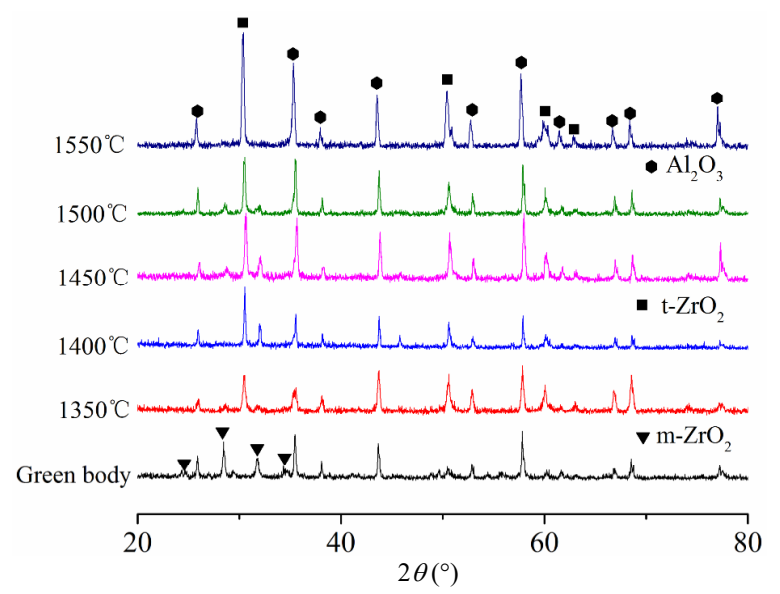

Fig. 9 XRD patterns of ZTA ceramics. studied. The green samples were sintered with a heating rate of $7{ }^{\circ} \mathrm{C} / \mathrm{min}$ for $30 \mathrm{~min}$ by a multi-mode microwave sintering furnace with auxiliary-heating insulation device, which was designed based on the principle of local caloric compensation. The highest hardness value of ZTA samples sintered at $1450{ }^{\circ} \mathrm{C}$ was $14.2 \mathrm{GPa}$. The highest bulk density of ZTA samples was $4.01 \mathrm{~kg} / \mathrm{m}^{3}$, which was sintered at $1500{ }^{\circ} \mathrm{C}$. The bending strength increased with increasing sintering temperature from 1350 to $1500{ }^{\circ} \mathrm{C}$ with the highest value of $435 \mathrm{MPa}$. With the increasing of sintering temperature, more and more microwave energy was absorbed within the entire sample and volumetric densification performed, phases shifted from $\mathrm{m}-\mathrm{ZrO}_{2}$ phase to $\mathrm{t}-\mathrm{ZrO}_{2}$ phase.

\section{Acknowledgements}

This work was sponsored by the National Natural Science Foundation of China (NSFC, No. 51172113).

\section{References}

[1] Exare C, Kiat J-M, Guiblin N, et al. Structural evolution of ZTA composites during synthesis and processing. $J$ Eur Ceram Soc 2015, 35: 1273-1283.

[2] Bartolomé JF, Smirnov A, Sommer F, et al. Sliding wear behavior of ZTA with different yttria stabilizer content. J Am Ceram Soc 2015, 98: 3981-3987.

[3] Oghbaei M, Mirzaee O. Microwave versus conventional sintering: A review of fundamentals, advantages and applications. J Alloys Compd 2010, 494: 175-189.

[4] Chatterjee A, Basak T, Ayappa KG. Analysis of microwave sintering of ceramics. AIChE J 1998, 44: 2302-2311.

[5] Bykov YV, Rybakov KI, Semenov VE. High-temperature microwave processing of materials. J Phys D: Appl Phys 2001, 34: R55.

[6] Clark DE, Sutton WH. Microwave processing of materials. Annu Rev Mater Sci 1996, 26: 299-331.

[7] Rybakov KI, Olevsky EA, Krikun EV. Microwave sintering: Fundamentals and modeling. J Am Ceram Soc 2013, 96: 1003-1020.

[8] Brosnan KH, Messing GL, Agrawal DK. Microwave sintering of alumina at $2.45 \mathrm{GHz}$. J Am Ceram Soc 2003, 86: $1307-1312$.

[9] $\mathrm{Lu} \mathrm{B}$, Wang Y, Sun XD, et al. Synthesis of $\mathrm{Sc}_{2} \mathrm{O}_{3}$ nanopowders and fabrication of transparent, two-step sintered $\mathrm{Sc}_{2} \mathrm{O}_{3}$ ceramics. Adv Appl Ceram 2012, 111: 389-392.

[10] Thuault A, Savary E, Bazin J, et al. Microwave sintering of large size pieces with complex shape. $J$ Mater Process Tech 2014, 214: 470-476.

[11] Kapoor AS. Microwave sintering of solid oxide fuel cell 
materials. Available at http://www.lib.ncsu.edu/resolver/ 1840.16/1150.

[12] Benavente R, Salvador MD, Penaranda-Foix FL, et al. Mechanical properties and microstructural evolution of alumina-zirconia nanocomposites by microwave sintering. Ceram Int 2014, 40: 11291-11297.

[13] Baeraky TA. Microwave measurements of the dielectric properties of silicon carbide at high temperature. Egypt J Sol 2002, 25: 263-273.

[14] Heuguet R, Marinel S, Thuault A, et al. Effects of the susceptor dielectric properties on the microwave sintering of alumina. J Am Ceram Soc 2013, 96: 3728-3736.

[15] Calambás Pulgarin HL, Albano MP. Sintering, microstrusture and hardness of different alumina-zirconia composites. Ceram Int 2014, 40: 5289-5298.
[16] Pian X, Fan B, Chen $\mathrm{H}$, et al. Preparation of $\mathrm{m}-\mathrm{ZrO}_{2}$ compacts by microwave sintering. Ceram Int 2014, 40: 10483-10488.

Open Access The articles published in this journal are distributed under the terms of the Creative Commons Attribution 4.0 International License (http://creativecommons. org/licenses/by/4.0/), which permits unrestricted use, distribution, and reproduction in any medium, provided you give appropriate credit to the original author(s) and the source, provide a link to the Creative Commons license, and indicate if changes were made. 